\title{
LA NUEVA ESTELA DE GUERRERO DE LAS BODEGUILLAS (ESPARRAGOSA DE LARES, BADAJOZ) Y EL PAISAJE CULTURAL DEL FINAL DE LA EDAD DEL BRONCE EN LA SERENA
}

\author{
THE NEW WARRIOR STELA OF LAS BODEGUILLAS (ESPARRAGOSA DE LARES, BADAJOZ) \\ AND THE CULTURAL LANDSCAPE OF THE END OF THE BRONZE AGE IN THE SERENA
}

\author{
IGNACIO PAVÓN SOLDEVILA* \\ DAVID MANUEL DUQUE ESPINO**
}

\begin{abstract}
Resumen: En la primera parte de este artículo se presenta la estela de guerrero de Las Bodeguillas, un nuevo ejemplar encontrado en Esparragosa de Lares (Badajoz), cuyo estudio iconográfico no sólo permite incluirla entre las más características del denominado "grupo del valle del Guadiana", sino también asignarle una cronología avanzada, ya del Bronce Final-Orientalizante. El trabajo continúa, en una segunda parte, con una valoración de lo que conocemos sobre el paisaje físico y cultural de este horizonte en la comarca de La Serena, ofreciendo una propuesta muy abierta sobre la diversidad de factores paleoeconómicos que soportaron su poblamiento protohistórico. Éste, si bien claramente rural, se muestra plenamente integrado en dinámicas de interacción con otros espacios de aparente mayor dinamismo, como la propia vega del Guadiana. Palabras claves: Estelas de guerrero, Bronce Final-Orientalizante, La Serena, poblamiento, paleoeconomía.
\end{abstract}

Como es sabido, desde el hallazgo y publicación en 1898 del primer ejemplar por D. Mario Roso de Luna, el conjunto formado por las estelas de guerrero y las estelas diademadas no ha dejado de aumentar, hasta superar ampliamente la centena y convertirse en los items arqueológicos más reconocibles de Extremadura. Si bien no exclusivas de la región extremeña, por su reiterada y

\footnotetext{
* Área de Prehistoria, Universidad de Extremadura.

** Investigador del Programa Ramón y Cajal del Ministerio de Ciencia e Innovación.
}

\begin{abstract}
In the first part of this paper the warrior stelae of The Bodeguilla is presented, it is a new exemplar found in Esparragosa de Lares (Badajoz), whose iconographic study not only enables the most features include the socalled "group Guadiana Valley" but also an advanced chronology, in the Late Bronze Age-Orientalizing Period. The work continues in a second part, with a valoration of what we know about the physical and cultural landscape of this horizon in the region of La Serena, offering a very open proposal on the diversity of paleoeconomical factors in protohistoric settlement. Although clearly rural, it is shown fully integrated in dynamics of interaction with other areas of apparently more dynamic, as the very fertile plain of the Guadiana.

Key words: Warrior stelae, Late Bronze Age-Orientalizing Period, La Serena, settlement, palaeoeconomy.
\end{abstract}

relativamente bien distribuida presencia las estelas han venido considerándose parte importante de su pretérita identidad -como denota, por ejemplo, la edición de un catálogo monográfico que conmemoró su nuevo y preferente tratamiento expositivo en el piso superior del patio noble del Museo Arqueológico Provincial de Badajoz (Domínguez et alii 2005)-; suscitando a la vez en algunos autores la evocación de un pasado heroico asimilable al de otros rincones de Europa y el Mediterráneo hacia el final de la Prehistoria (Pavón, e.p.). Gran parte del magnético atractivo que despiertan, tanto en 
profanos como en especialistas, deviene precisamente de su carácter icónico, verdaderamente anómalo, dicho sea de paso, en un mundo tan poco dado a los excesos en el plano estrictamente figurativo como lo es el del final de la Edad del Bronce en el suroeste peninsular. En no menor medida, igualmente seductor resulta su recóndito significado, incentivo para mil y una teorías y especulativas divagaciones.

En este marco, la investigación se ha sentido tentada en más de una ocasión por la posibilidad de dar una respuesta total al fenómeno de las estelas, precisamente desde el abordaje a partir de la valoración de esos monumentos en sí mismos, en su iconografía (Almagro Basch 1966; Pingel 1974; Almagro Gorbea 1977). En el otro extremo, los últimos tiempos han conocido intentos por extraer el significado último de las estelas del propio marco físico que las rodeó (Barceló 1989; Celestino 1990 y 2001; Ruiz-Gálvez y Galán 1991; Galán 1993), pasándose así a un polo complementario que necesariamente debe tenerse en cuenta. Pero hemos de convenir que las estelas formaron parte de un paisaje cultural, más que estrictamente natural, que como tal debe contemplarse valorando de forma integral los referentes más diversos de su tiempo, fueran éstos ambientales, poblacionales, paleo-económicos, artísticos, etc. La línea seguida en este trabajo -convergente con esa necesidad reclamada no hace mucho por otros autores (Murillo et alii 2005: 42; Enríquez 2006)- participa de la idoneidad de insistir, sobre todo, en la ponderación del marco contrastable de las estelas, para lo que valoraremos, al hilo de la oportunidad de dar a conocer en sus detalles el nuevo hallazgo de Esparragosa de Lares (Badajoz), una zona tan densa en este tipo de monumentos y reconocida por la bibliografía como es la del sureste extremeño.

\section{LA ESTELA DE LAS BODEGUILLAS O ESPARRAGOSA DE LARES III}

El descubrimiento de la estela de Esparragosa de Lares III, o Las Bodeguillas, tuvo lugar de una forma fortuita en el año 2003, como consecuencia de las labores de arado con tractor desarrolladas en una propiedad de D. Luis Sanz Calderón en la finca homónima, quien levantó una piedra alargada de gran tamaño que inicialmente sólo arrastró hasta el límite de la parcela. Algunos meses más tarde, tras advertir una serie de motivos grabados ya limpios por efecto de las lluvias, decidió el traslado a su cortijo, donde D. Felipe Redondo Milara, entonces alumno de la licenciatura de Historia en la Universidad de Extremadura, vecino del lugar y pariente del descubridor, reconoció la naturaleza y el interés del hallazgo, que puso de inmediato en conocimiento de algunos de sus profesores en la UEX. De hecho, nuestro colega J. J. Enríquez, que por aquél entonces ultimaba un artículo sobre las estelas, estimó oportuno dejar al menos constancia del nuevo hallazgo en una sucinta nota a la que acompañó de una fotografía prestamente facilitada por el informante (Enríquez 2006: 167); quedando desde entonces la pieza en el olvido. A lo largo del mes de octubre de 2008 quienes suscribimos este artículo tuvimos noticias por primera vez, gracias al mencionado Sr. Redondo, del paradero de la pieza. Las imprecisiones en su descripción inicial, deficiente documentación, y también la posibilidad de conocer en detalle el contexto de aparición, nos llevaron a desplazarnos a esa localidad en los últimos días de 2008, con la intención de recabar la máxima información posible. Por su mediación nos fue posible incluso contactar con el descubridor, quien amablemente nos condujo al lugar exacto del hallazgo, permitiéndonos más tarde hacer un calco, fotografiar y describir la estela, para encomendarnos finalmente su traslado y donación al Museo Arqueológico Provincial de Badajoz, en una iniciativa desinteresada que sólo cabe elogiar y agradecer.

Dicho hallazgo se había producido en la gran zona interfluvial entre el Guadiana y el Zújar, a poco más de unos $11 \mathrm{Km}$ al oeste de la mencionada localidad de Esparragosa de Lares, y, según nos indicó su descubridor, en un punto que se ubica exactamente en las coordenadas $38^{\circ} 58^{\prime} 5542^{\prime \prime}$ N. y 5 $5^{\circ} 23^{\prime} 4639$ ' W. Se trata de un escenario no lejano -entre 1 y $2 \mathrm{Km}$ al oeste-del paraje de Las Puercas, al que se ha venido atribuyendo, hasta hace poco (Enríquez 2006: 163), la procedencia de la estela de Esparragosa de Lares I; con la que guarda, como se verá, notable parecido. No se muestra, sin embargo, como un lugar dotado de especiales características; no es ni un alto ni un valle; no se encuentra cerca de ningún curso de agua; no dispone de dominio visual ni posición estratégica. A lo sumo, sólo cabe referir su no excesiva distancia de uno de los caminos ganaderos históricos más importantes de la región, como es el de la Cañada Real Leonesa Oriental (Estepa 2000: 218-219; Rodríguez 2004: 420-421); pero tampoco está exactamente a pie de la ruta trashumante. Por otra parte, el reconocimiento directo de la parcela donde apareció y las colindantes -muy modificadas respecto al aspecto que presentaban en el momento del hallazgo, según nuestros informantes- no proporcionó ningún tipo de información adicional, salvo la constatación 

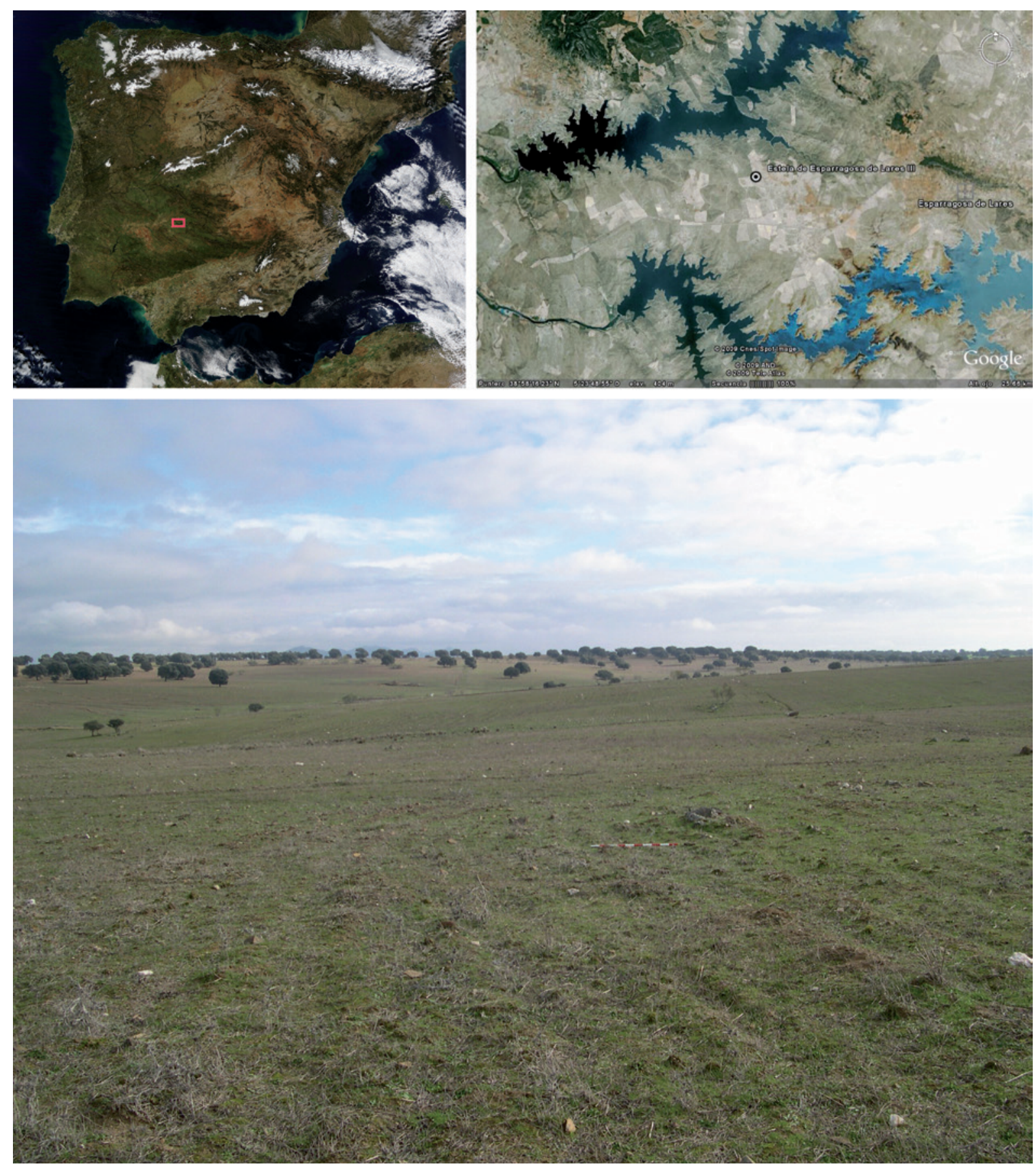

Figura 1. Localización espacial de la estela de Esparragosa de Lares III

en superficie de la más absoluta ausencia de restos arqueológicos de cualquier tipo, y la presencia de afloramientos rocosos de naturaleza similar a la de la materia prima del soporte empleado para fabricar la estela (Fig. 1). Convendría recordar, como han hecho recurrentemente otros autores, que el entorno inmediato de las estelas a menudo se suele caracterizar por la ausencia de todo dato digno de interés. Dejando a un lado las novedosas reflexiones que sobre ello han vertido en esta misma revista Tejera et alii (2006), y restringiéndonos a la zona en estudio, una conclusión planteada por Enríquez (2006) ha insistido en la falta de correspondencia 

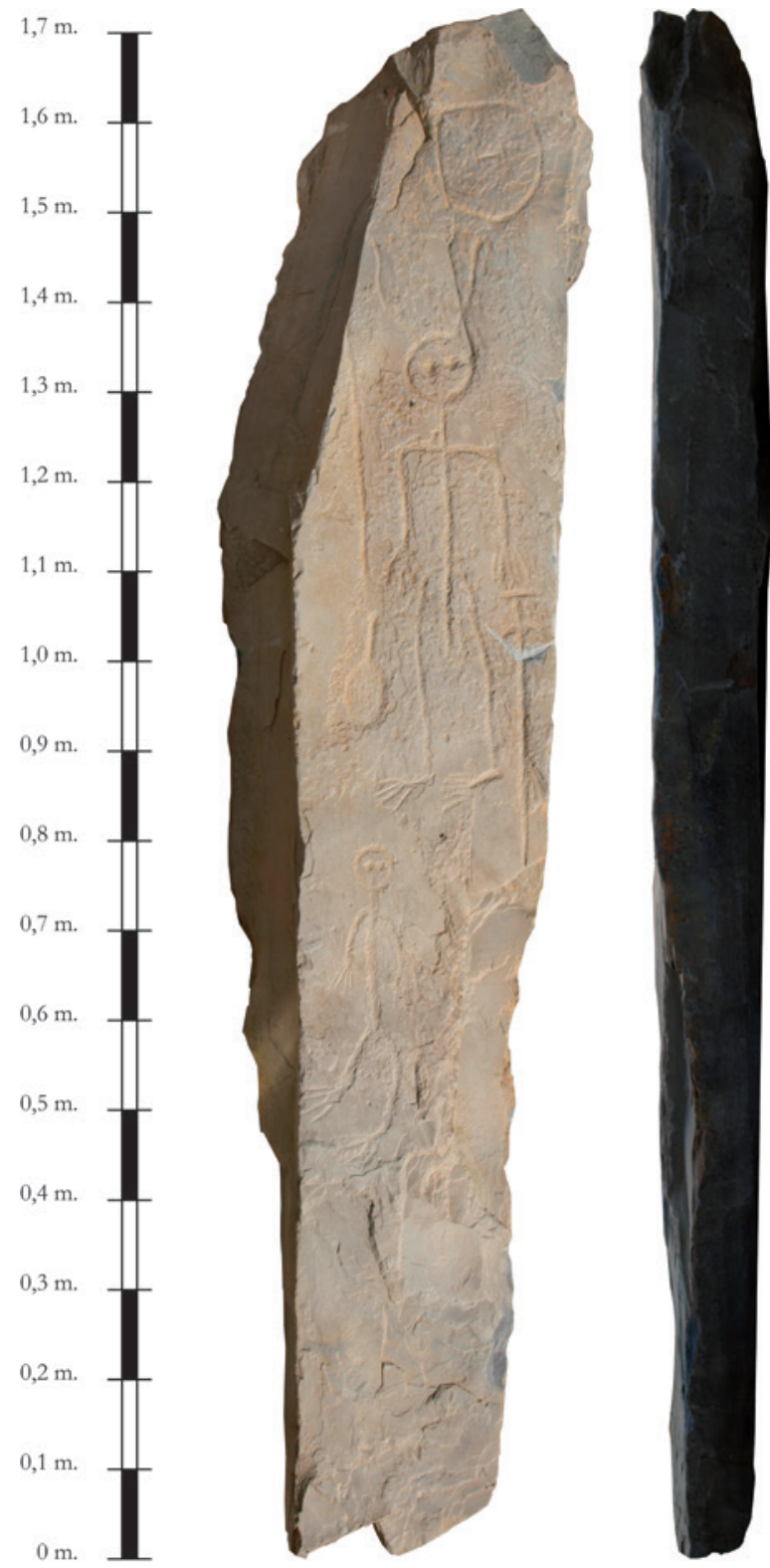

Figura 2. Estela de Esparragosa de Lares III.

entre los anodinos contextos conocidos por excavación y los propiamente funerarios; aunque ello no privaría a las estelas, en su opinión, de un sentido trascendente.

El soporte sobre el que fabricó la estela está constituido por un bloque betiliforme de pizarra silícea ${ }^{1}$ de $176,5 \times 28,4 \times 13 \mathrm{~cm}$, que no ofrece ninguna huella de

1. Agradecemos la determinación de la materia prima, junto a otras precisiones técnicas, al Dr. D. Moisés Ponce de León Iglesias (Universidad de Rennes 1), que tuvo la amabilidad de reconocer la pieza el pasado mes de mayo de 2009. tratamiento previo en la cara donde se localiza la decoración. El campo figurativo, que se ubica en la parte superior, ocupa $115 \mathrm{~cm}$-casi el $70 \%$ de la pieza-, permaneciendo el resto en reserva; de lo que se deduce claramente su utilización como una verdadera estela, es decir hincada verticalmente en la tierra para ser vista. Si tenemos en cuenta que en la zona Guadiana-Zújar la altura de las estelas, muy variable, no sobrepasa por término medio los $120 \mathrm{~cm}$ (Celestino 2001: 82), podemos considerar a la de Las Bodeguillas como una de las más esbeltas, con un alzado, curiosamente, similar al de la ya mencionada estela de Esparragosa de Lares I, hallada hace años fuera de contexto (Enríquez y Celestino 1984: 240). En la generalidad del fenómeno, formaría parte del segundo grupo más numeroso, el de los soportes de entre 160-180 cm (Harrison 2004: 33) (Fig. 2).

Uno de los aspectos más interesantes que permite estudiar esta nueva estela es el relacionado con la técnica de grabado, que, por lo que hemos podido observar, se desarrolló en una serie de pasos sucesivos. En primer lugar se procedió a marcar un esquema de la composición con la ayuda de un punzón que, por las incisiones advertidas en algunas zonas, no siempre logró el artífice controlar con precisión. A continuación, y sobre el boceto anterior, se ejecutaron todos los motivos -salvo uno que cabe interpretar como un peine, sobre el que volveremos más tarde- mediante una percusión continua o técnica de piqueteado, realizada con la ayuda de un cincel posiblemente de bronce, que logró reproducir las figuras con un rebaje medio de en torno a los $2 \mathrm{~mm}$. Esta generalización del rebaje es una de las características que los especialistas han advertido en las estelas de la zona (Celestino 2001: 88). Finalmente, se volvió a emplear el punzón para, mediante incisión, marcar detalles en algunos de los motivos (Fig. 3), o a fin de realizar con la ayuda de dicha herramienta alguna figura de principio a fin (como en el caso del mencionado posible peine).

En cuanto a la composición escénica -clave en opinión de Celestino (2001: 97) para descubrir el significado y cronología de estos monumentos-, cabe mencionar de entrada que la buena conservación de la pieza, apenas perjudicada por un fragmento saltado de antiguo en el lateral derecho de la zona inferior, y a lo sumo otro en la parte superior izquierda de la figuración ${ }^{2}$, permite en este caso un acercamiento relativamente solvente. Así, compartiendo rasgos que resultan reconocibles en otras estelas de las zonas más

2. En todas nuestras descripciones empleamos estos términos desde el punto de vista de quien contempla la pieza frontalmente. 


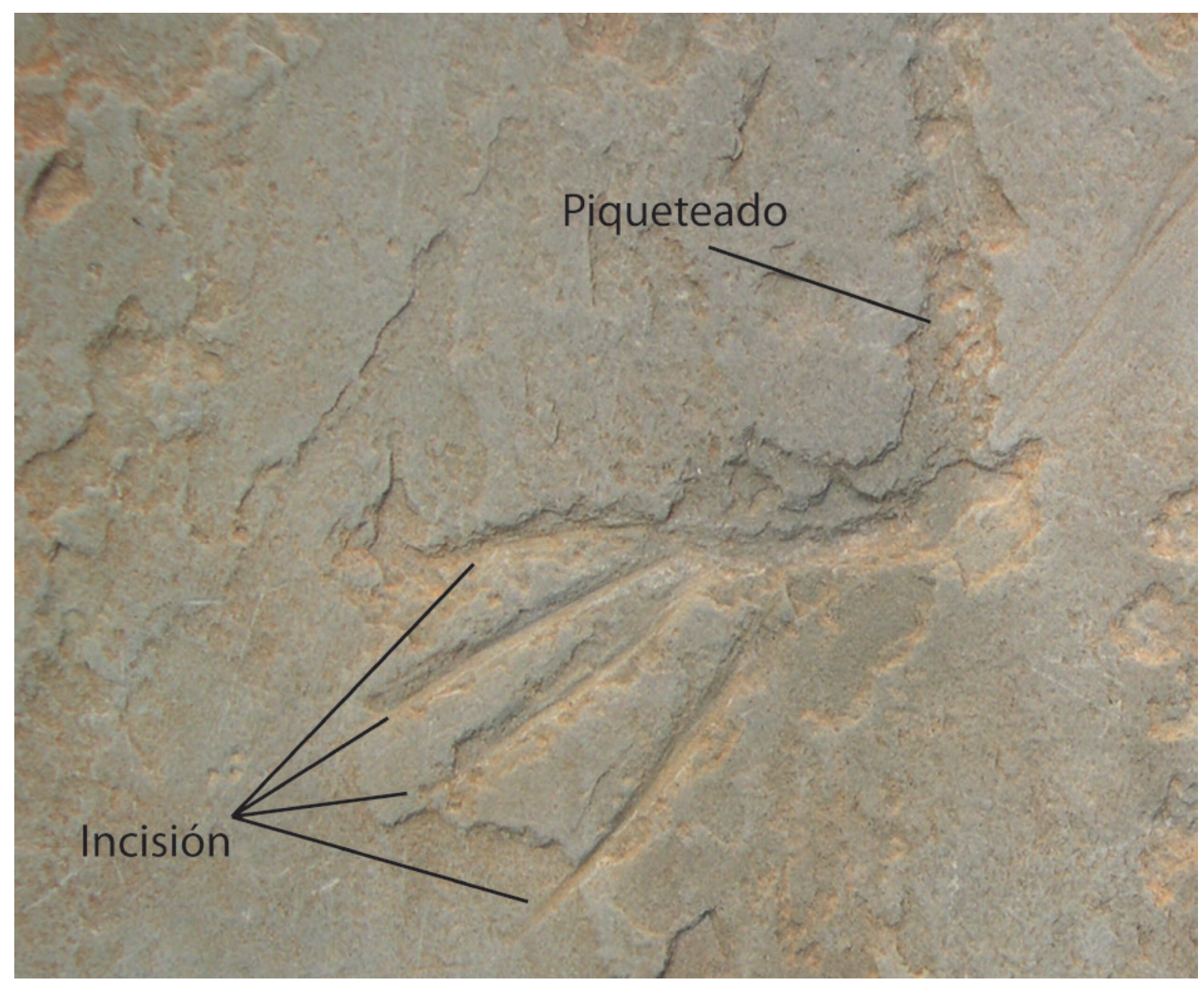

Figura 3. Técnicas de grabado.

meridionales (Celestino 1990: 54; Barceló 1989: 190), el mayor protagonismo parece reservado a la figura del guerrero, dotado aquí de un casco de cuernos, que aparece rodeado por otros elementos comunes en este tipo de composiciones, como el escudo (parte superior), la lanza (a su derecha) y la espada (a su izquierda), que se completan con las representaciones del espejo, el probable peine y otro antropomorfo a menor escala (parte inferior) (Fig. 4). En función de todo ello podríamos, pues, vincularla en su estructura iconográfica general al grupo, característico de los valles del Guadiana y del Guadalquivir, que integran las estelas con representaciones antropomorfas centrales de S. Celestino (1990: 55; 2001: 94). Un contexto éste en el que cabe admitir un cierto aire de familia entre el nuevo ejemplar y los ya conocidos de Magacela, Esparragosa de Lares I, Fuente de Cantos, Burguillos y Écija II; y en el que no se debe dejar de anotar, en particular, la presencia del mismo número y motivos grabados en ésta de Esparragosa de Lares III y en la estela de Montemayor (Córdoba) (Ferrer 1999), aunque con los lógicos matices formales y de distribución.

El antropomorfo de mayor tamaño, tocado con un casco de cuernos, presenta una longitud total de 63,5 $\mathrm{cm}$, medida desde las extremidades inferiores hasta el apéndice más sobresaliente de la protección defensiva, restringida a $48 \mathrm{~cm}$ en lo que es sólo el cuerpo. En lo que es éste estrictamente, su cabeza, una circunferencia casi perfecta de $7,8 \mathrm{~cm}$ de diámetro, presenta en la cara dos ojos grabados; un rasgo muy poco frecuente en la iconografía de estos ítems, que sólo en las estelas de Torrejón el Rubio III (Fernández 1950; Celestino 2001: 332), Cortijo de la Reina II (Murillo et alii 2005: 26 y 33) y Gomes Aires (Almodóvar) (Celestino 2001: 445) ofrece casos similares. Una presencia de detalles faciales que, dicho sea de paso, tampoco es desconocida 


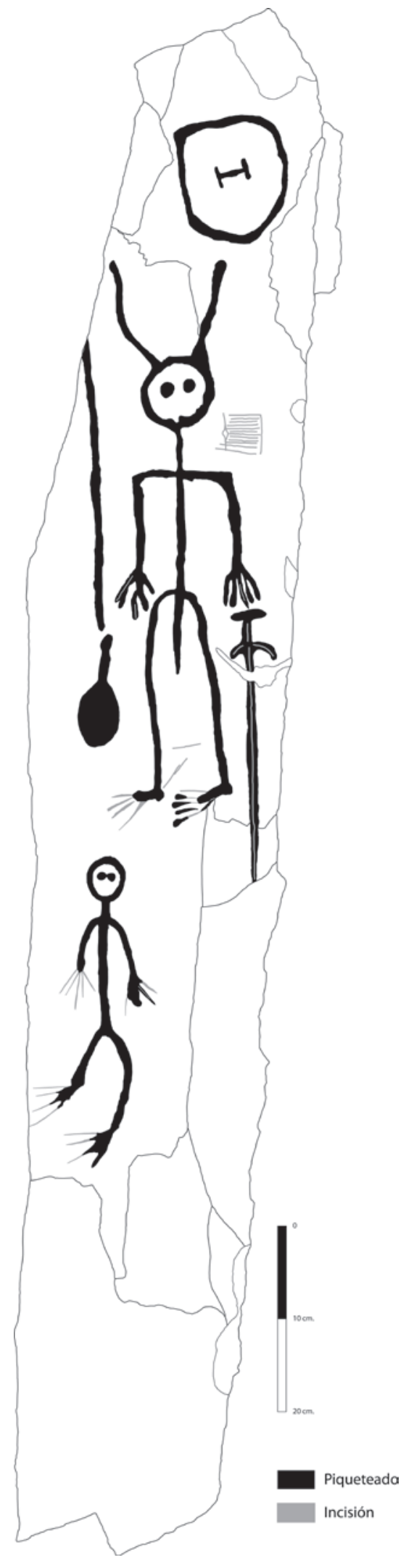

entre las femeninas o diademadas, como atestiguan los ejemplares de Valera Julia (Bodonal de la Sierra) (Domínguez et alii 2005: 39) y El Oreganal (Torrejón el Rubio II) (Fernández 1950; Celestino 2001: 331). El cuello, comparativamente muy desarrollado, le une a un tronco recto y simplemente lineal, de $12,3 \mathrm{~cm}$, que resulta mayoritario entre las estelas al sur del Guadiana (Celestino 2001: 93) y que según R. Harrison (2004: 93) define, en su ausencia de volumen, un prototipo humano -stick figures- iconográficamente muy esquemático. Curiosamente, resulta muy minoritaria entre las estelas de guerrero la representación del atributo sexual masculino; pero en ésta de Las Bodeguillas el falo sí se explicita claramente, uniéndose así a las de El Viso I (Almagro Gorbea 1977; Celestino 2001: 394), Aldea del Rey III (Valiente y Prado 1979; Celestino 2001: 413), Ategua (Bernier 1969; Celestino 2001: 430), Ervidel II (Gomes y Monteiro 1977; Celestino 2001: 447) y Cerro Muriano I (Murillo et alii 2005: 19). Las extremidades superiores, por su parte, se separan del tronco con un primer trazo horizontal -es decir, perpendicular a él, representando los hombros- que después continúa con un giro de noventa grados hacia abajo, hasta desembocar en las manos. Si los hombros y brazos están acabados en piqueteado, las manos -reducidas muy esquemáticamente a dedos que salen radialmente- se han completado mediante incisión sobre el trazo de algunos dedos. Por su parte, las inferiores - con un trazo inicial en "U" invertida- acaban igualmente en unos pies que constan de un primer trazo horizontal piqueteado, dispuesto hacia la izquierda, y cuatro dedos incisos en cada uno. Algunos de estos esquematismos, como esa disposición angular en la relación hombro-brazo o la representación de los dedos en manos o pies, son compartidos por bastantes de los antropomorfos representados en las estelas (Celestino 2001: 321 y ss.; Murillo et alii 2005; García et alii 2006: 139), incluido el ya mencionado personaje principal de Montemayor (Córdoba) (Ferrer 1999: 66), sin que de su análisis pormenorizado puedan extraerse conclusiones reseñables. Sólo atendiendo a otros detalles, como su relación con los cascos grabados, podría tal vez decirse algo más.

Los cascos constituyen uno de los elementos más estudiados de estas representaciones, no tanto por su abundancia -están presentes en torno a la tercera parte de los casos (Celestino 2001: 151)- como por la afinidad que presentan los dos tipos en ellas identificables -el casco cónico y el de cuernos- con otros no

Figura 4. Calco de la estela de Esparragosa de Lares III. 
considerados autóctonos, pero bien conocidos arqueológicamente $\mathrm{y}$, según se ha propuesto, representativos de diferentes influencias culturales. En concreto, el de la estela de Las Bodeguillas pertenece a una subvariante que puede advertirse dentro de los segundos, la de los cascos de cuernos liriformes (Fig. 5a). Como ha señalado el propio S. Celestino (2001: 157), el Guadiana-Zújar constituye la zona, dentro de la geografía de las estelas, donde más se generaliza la representación del casco de cuernos, coincidiendo con el mayor esquematismo de los monumentos. Casos como los de Valdetorres I, Magacela, El Viso I y VI, Alamillo, Esparragosa de Lares I, y ahora Esparragosa de Lares III, parecer efectivamente corroborarlo. Además, en esa línea, no deja de resultar sorprendente el gran parecido iconográfico que presentan los antropomorfos coronados por cascos de cuernos y con extremidades -superiores o inferiores- digitadas de un buen número de estelas (Harrison 2004: 142) que sugeriría pensar en algún tipo de nexo entre ellas. Si bien no parece haber total unanimidad en lo que se refiere a la zona de procedencia originaria de los cascos de cuernos -aunque Harrison (2004: 143-144) se decanta hoy concluyentemente por el ámbito mediterráneo- es atractiva la hipótesis de Celestino (2001: 158) sobre la posibilidad de que provenientes de un influjo mediterráneo, al parecer exclusivo de un momento intermedio de la serie, sustituyeran a los cascos de cimera, de posible origen europeo, llegados previamente. Cascos de cuernos que, a decir de Harrison (2005: 144), dotarían de un carácter aristocrático, o elitista, a su beligerante portador; $\mathrm{o}$, alternativamente, de una condición heroica o sobrehumana, como propone Bendala (2000: 76-77).

Por el contrario, escudos, espadas y lanzas pasan por ser en origen los elementos más idiosincrásicos es decir, más autóctonos, atlánticos o representativos de la población local del Suroeste durante el Bronce Final- de las estelas, estando todos presentes en el nuevo ejemplar de Las Bodeguillas. Su estudio ha ofrecido, no obstante, resultados dispares. Entre ellos la lanza constituye, tal vez, el más anodino. Consiste simplemente en un astil de $31 \mathrm{~cm}$ de longitud piqueteado a la izquierda, hacia la parte superior, del antropomorfo mayor, cuya punta o no se ha definido suficientemente o se ha perdido, lo cual impide mayor comentario, salvo el derivado de recordar que en la zona de estudio su presencia es alta, superando el $75 \%$ de los casos (Celestino 2001: 101).

La espada se grabó en esta estela de una forma exenta y con una técnica mixta. Ubicada a la derecha, en un plano inferior, del antropomorfo de mayor tamaño, presenta una longitud máxima conservada de $29,1 \mathrm{~cm}$. Sus rasgos más sobresalientes son los apreciables en la zona de la empuñadura, sólo afectada por una erosión reciente -posiblemente del momento de su descubrimiento- donde destacan un pomo y una guarda, de traza curvilínea, muy desarrollados (Fig. 5 b). Con posterioridad a su definición mediante el piqueteado, se optó por usar de nuevo el punzón, que resalta en su incisión tanto el eje de la hoja como el de la guarda, suscitándonos la duda sobre si así pretendía el artífice sugerir el eventual nervio central de la primera, o los posibles calados en la segunda. Si bien ha sido muy grande el esfuerzo de la investigación por relacionar los tipos representados en las estelas con hojas reales, uno de sus mayores conocedores, S. Celestino (2001: 107), alertaba sobre el sentido esencialmente simbólico -emblemático de un cierto status social-de las mismas. También J. F. Murillo (1994a: 24), en una llamada al comedimiento, ha apuntado los peligros de forzar las similitudes que pueden hacerse partiendo de unos grafismos tan tendentes al esquematismo como los que se reflejan sobre las estelas y, consecuentemente, las problemáticas conclusiones crono-culturales de ahí derivadas.

No obstante, un reciente y sistemático estudio sobre las espadas del Bronce Final en el Mediterráneo Occidental no ha escatimado en recorrer esa senda (Branhdherm 2007: 21-25 y apéndice D), planteando una sugerente perspectiva que trataremos aquí de contemplar para valorar la peculiar espada de la estela de Las Bodeguillas. D. Brandherm, crítico en parte con el escepticismo que a veces exhiben los autores precedentes, no deja de reconocer una serie de variables que efectivamente limitan el proceso de diagnosis tipológica, pero a la vez aporta una minuciosa clasificación de las espadas grabadas en las estelas que desgrana hasta en una docena de tipos, entre los que, por sus similitudes al ejemplar que ahora estudiamos, fijaremos nuestra atención en los denominados G, H e I. Los dos primeros comparten rasgos comunes, como la empuñadura diferenciada con la guarda cruciforme y el pomo desarrollado en " $T$ ", pero se diferencian en la hoja, claramente pistiliforme en el primer caso $(\mathrm{G}) \mathrm{y}$, por el contrario, más parecida a las de las espadas de "lengua de carpa" en el segundo (H). Por problemas de conservación, desconocemos el extremo distal de la hoja de Las Bodeguillas, pero nada hace pensar que se trate de un ejemplar de la modalidad pistiliforme. Curiosamente, Brandherm (2007: 145) ha apuntado que el principal inconveniente que presentan estos dos tipos estriba en que guardas estrictamente cruciformes -como las representadas en 
las que integran ambos grupos- no se conocen entre las espadas del Bronce Final, si bien los pomos en "T" sí son muy comunes en las espadas del tipo Huelva. Frente a ello, cabría la posibilidad de que la guarda curvada de esta nueva estela de Esparragosa tal vez pudiera relacionarse con una representación de intencionalidad más "realista". Por su parte, las del tipo I lucen también empuñaduras diferenciadas con guarda cruciforme y pomo desarrollado en " $T$ ", pero presentan hojas de filos paralelos o subparalelos, más parecidas a la representada en nuestra estela. Para estas últimas se ha propuesto una cronología a caballo entre las fases Blackmoor/Braud/Huelva y Ewart Park/Vénat/Sa Idda, en un momento avanzado, por tanto, del Bronce Final. Anotemos, finalmente, que mientras las estelas con espadas del tipo $\mathrm{H}$ se extienden hasta hoy a lo largo de la mayor parte de la cuenca del Guadiana, las del tipo I se distribuyen sobre todo por el Guadalquivir y, en menor medida, por la cuenca del Zújar (Brandherm 2007: 144, 146 y lámina 53).

Una cronología también avanzada es la que se desprende, en principio, del estudio del escudo. El de Las Bodeguillas, representado mediante piqueteado sobre el guerrero, en la parte superior de la estela, ofrece un diámetro de 13,6 cm. De esa destacada posición cabe deducir su especial simbolismo, que comparte con otros muchos ejemplares; resultando excepcional su ausencia. Igualmente, se trata de uno de los motivos tradicionalmente representados con mayor lujo de detalles en las estelas, por lo que la falta de ellos en nuestro ejemplar, sólo exceptuada por la representación de una manilla, asidero o abrazadera en "I" en el centro de esta arma defensiva, pudiera poseer cierto valor informativo (Fig. 5 c). De este modo, puede anotarse que no se trata de un escudo con escotadura en "U/V" -o tipo Herzsprung-, habitual en bastantes ejemplares, sino de un escudo circular sin círculos concéntricos, que encajaría bien dentro de la variante "a" del tipo III de Celestino (2001: 123-124), de la que además sólo se conoce otro caso, curiosamente en la muy cercana estela de Las Puercas (Esparragosa de Lares I) (Domínguez et alii 2005: 27). Similitud que, debe admitirse, armonizaría bien con la teoría de Celestino (2001: 151) a propósito del valor de los escudos como elementos identitarios. En opinión de este investigador (2001: 149) la extensión de tales escudos redondos, sin escotaduras pero realizados aún a base de círculos concéntricos, sería temprana dentro del desarrollo cronológico de estos monumentos; pero la ausencia de detalles como el claveteado podría avalar la presencia de nuevos escudos procedentes de otras áreas exteriores a la Península, principalmente mediterráneas, algo antes de la colonización fenicia. Un argumento, en suma, para defender la posible fecha ya tardía del ejemplar aquí representado; salvedad hecha del notable esquematismo reconocido en las estelas de la zona, que obliga obviamente a extremar la prudencia.

No obstante, la representación de otros dos elementos de presumible procedencia mediterránea también está presente aquí; aunque no se trata de armas, sino más bien de objetos que en el contexto protohistórico conllevan, según todos los especialistas, una connotación prestigiosa y, posiblemente, funeraria. Uno de ellos es el espejo, representado, con una longitud total de $12,5 \mathrm{~cm}$, bajo la lanza, a la izquierda del guerrero, no lejos de su mano y bien orientado para ser cogido por ésta, en una ubicación que es habitual (Celestino 2001: 166). Como sucede en los demás casos documentados al sur del Guadiana, que son abundantes, la cazoleta (aquí ligeramente ovalada) está totalmente rebajada y el mango -de unos $5 \mathrm{~cm}$ de longitud-se define mediante piqueteado (Fig. 5 d). Un mango que, en este caso, no ofrece detalles, por lo que -con todo lo dichonuestro espejo podría incluirse en el grupo B de Harrison (2004: 153), por su simpleza uno de los menos proclives al comentario, que también integran los de Torrejón el Rubio IV, Brozas, Tres Arroyos de Alburquerque, Zarza de Montánchez, Solana de Cabañas y Zarza Capilla III, además de los cercanos casos de Esparragosa de Lares I y II. La constatación de la existencia de una superficie amorfa con huellas de piqueteado, a la izquierda y no lejos de la representación del espejo, sugiere la posibilidad de que el autor de la ornamentación procediera a una elaboración fallida, incluso de ese mismo motivo, antes de grabar el definitivo; lo que no deja de ser extraño si tenemos en cuenta su simplicidad. En el mundo de las estelas, no obstante, no son desconocidas las redefiniciones de la composición escénica de determinadas piezas, ni la existencia de errores después subsanados por el grabador (Celestino 2001: 89 y 91).

Por otra parte, la aparición de los peines en las estelas es, a decir de Celestino (2001: 165 y 167-168), una consecuencia directa, sobre todo en el sur extremeño y Andalucía, de la llegada de los ejemplares de marfil traídos por los fenicios, o a lo sumo por sus más inmediatos predecesores en la actividad comercial (Celestino, 2008). En el Guadiana-Zújar su presencia se restringe a una tercera parte de las estelas; a veces, como aquí, ubicados junto a la cabeza del antropomorfo protagonista. Tipológicamente el ejemplar que como tal podría interpretarse en Las Bodeguillas es, sin duda, 

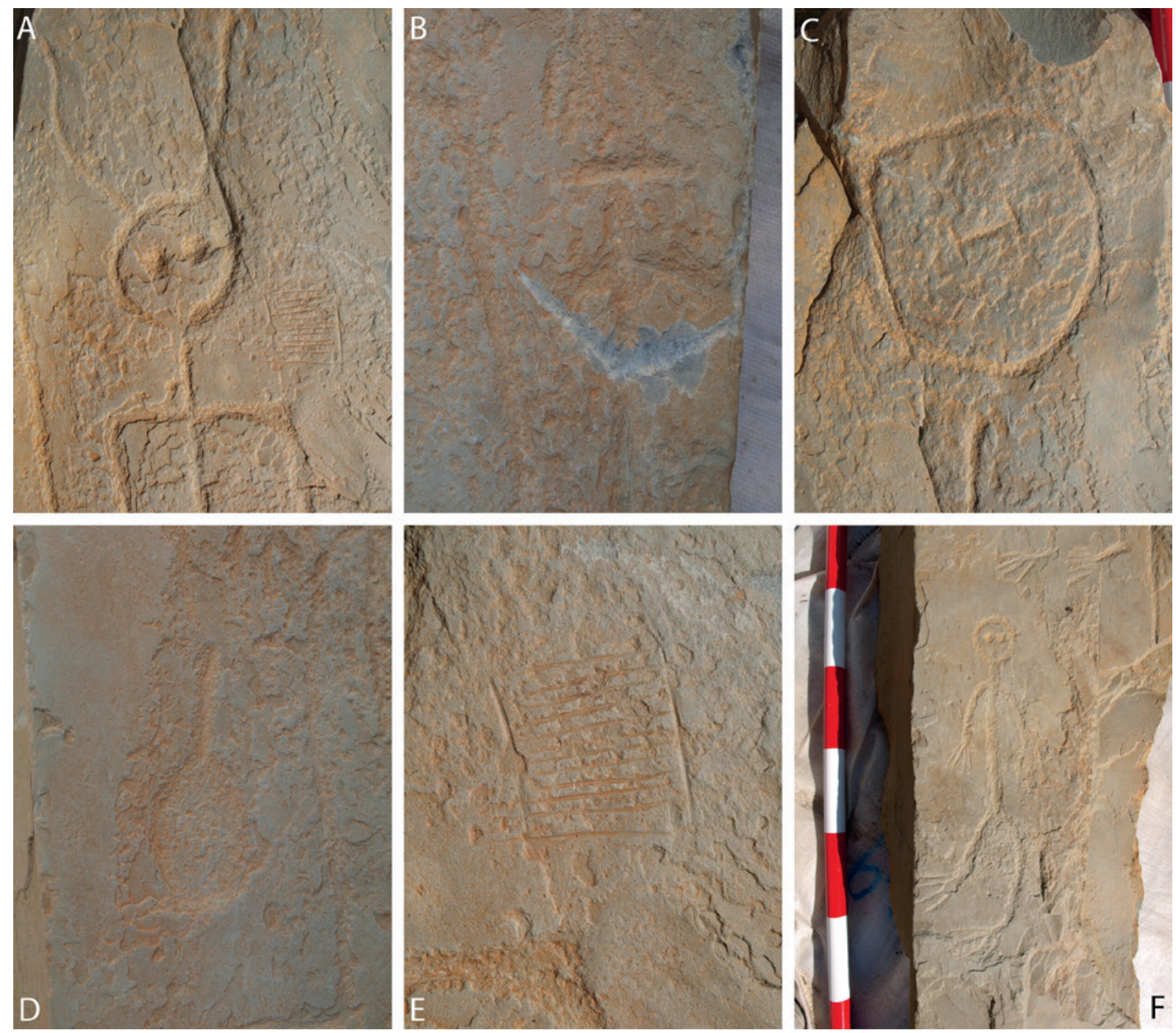

Figura 5. Detalles de la estela de Esparragosa de Lares III

de los más complejos o abstractos, pues no consta de un simple trazo grueso del que salgan varias incisiones perpendiculares más finas, sino que ofrece una estructura rectangular (Fig. 5 e), sorprendentemente con notable parecido a la de otros motivos, reticulados o escaleriformes, incisos no sobre soportes exentos, sino sobre paneles pizarrosos -como sucede, entre otros, en el panel del Arroyo del Campo del Toro (Campanario) (Domínguez y Aldecoa 2007: 312-314)-del arte rupestre al aire libre en La Serena. Con unas dimensiones de 4,9 x 4,1 cm, se define como una suerte de rectángulo surcado de lado a lado por hasta 12 trazos horizontales, de cuyo marco se salen los dos inferiores, tal vez por impericia del artífice. Pero la singular elaboración de este posible peine, de principio a fin mediante la técnica de la incisión, nos sitúa ante un plano diacrónico difícil de valorar. En todo caso, mientras el esbozo erróneo y la adición de detalles antes comentados (espejo, extremidades del antropomorfo, guarda y hoja de la espada) implican una continuidad esencial en el proceso creativo, creemos que la elaboración marcadamente diferente del peine pudiera deberse tal vez a una inclusión postrera en el esquema general, pues la necesidad de hacer uso de una técnica especial para ese motivo no parece probable en este caso, al haber otros en los que este tipo de objeto se recrea usando la misma técnica que en el resto de los figurados -El Corchito de Cabeza del Buey (Domínguez et alii 2005: 11); Las Puercas (Esparragosa de Lares I) (Domínguez et alii 2005: 27)-; a no ser que así se pretendiese sugerir tal

ISSN: 1133-4525 ISSN-e: 2255-3924 
vez la fragilidad del objeto. No obstante, debe anotarse que también en la zona conocemos algún otro caso en el que se siguen pautas similares a las observadas en la estela de Las Bodeguillas a la hora de representar el peine con una técnica diferente a la de los otros motivos -La Yuntilla Alta de Cabeza del Buey (Domínguez et alii 2005: 19)-; y también fuera de ella, como en la estela de Brozas (Mac White 1947; Celestino 2001: 338 ), donde dicha circunstancia ha dado pie a defender abiertamente la posterioridad cronológica de la grabación del peine respecto a los otros motivos (Celestino 2001: 165). En todos estos casos nos resulta imposible determinar el lapso temporal que media entre uno y otro episodio; pero estas maniobras técnicas postreras sobre las estelas encajan bastante bien con la adición de nuevos ítems mediterráneos de prestigio -quién sabe si como una forma de actualizar el mensaje que se trataba de transmitir en origen (Harrison 2004: 76 ) - a las armas hasta entonces ostentadoras del poder: serían las estelas como testigos de cambio/continuidad en tránsito del final de la Edad del Bronce al comienzo de la Edad de Hierro; pues, como muy bien ha recordado E. Ferrer (1999: 70) no es aventurado proponer una perduración cronológica de las estelas durante el Período Orientalizante.

Un último motivo del ejemplar de Las Bodeguillas podría sugerir también, aunque se trata de un tópico no exento de polémica, las transformaciones sociopolíticas vividas en ese tiempo: el otro antropomorfo. Situado en la parte inferior izquierda de la representación, con una longitud total de $34 \mathrm{~cm}$, se elaboró con la misma técnica mixta referida para la otra figura humana; pero, aunque coincide en algunos detalles figurativos con aquélla (detalles de ojos, manos y pies), su iconografía difiere en otros que estimamos importantes, porque pueden conllevar la transmisión de un mensaje. Nos estamos refiriendo, en particular, a la menor escala de este nuevo antropomorfo y a las ausencias de tocado, en su cabeza, y atributo sexual masculino (Fig. 5 f). En relación con esto último, cabe decir que ello no implica que se trate de un personaje femenino, casi siempre bien explicitado en las estelas a través de detalles por lo general inequívocos, sino tal vez de un infante o alguien no dotado de los valores simbólicos que -fueran cuales fuesen- transmite la representación fálica. Por su parte, la ausencia de casco debe relacionarse, de entrada, con la de cualquiera de los elementos que más arriba acompañan al otro individuo, con lo que ello implica de contraste (posesión/no posesión) entre ambas figuras; pero, además, no debe olvidarse el mencionado carácter simbólico también atribuido a esta clase de tocados, que nos sitúa ante un segundo nivel de diferenciación (dignidad/no dignidad terrenal o espiritual). Finalmente, la menor escala del nuevo personaje permite vincular la de Las Bodeguillas a esas otras tantas estelas (las de El Viso IV, Carmona, Burguillos, Los Palacios y Ervidel II) -a las que tal vez quepa sumar las de Guadálmez y Cortijo de la Reina I (Murillo et alii 2005: 10 y 26)- que han conducido a R. Harrison (2004: 101, Fig. 6.15) a considerar una modalidad específica de composición figurativa definida por la presencia de figuras antropomorfas pareadas en jerarquía. Dicho lo cual, hemos de confesar que resulta un motivo que dota a esta estela de una cierta polisemia y la hace proclive al debate; pues mientras resulta, efectivamente, posible rastrear tras su composición general la huella, tal vez, de formas incipientes de patronazgo o clientela, como las propuestas por Mederos y Harrison (1996) o el propio A. Ruiz (1996), no es menos cierto que, de admitirse el segundo antropomorfo como un infante, acaso podría valorarse como una prueba iconográfica en favor formas emergentes de poder adscrito a través de la herencia, como L. García Sanjuán (1999: 86-87) ha insinuado también para esta época o poco antes. Sea como fuere, ambas lecturas al margen de otras que han llegado a proponer para los antropomorfos secundarios la condición de esclavos, o incluso de víctimas en sacrificios rituales-suscitan, en principio, la emergencia de una sociedad progresivamente más compleja, como sin duda fue la que se dio entre el final de la Edad del Bronce y los comienzos de la Edad del Hierro, el tiempo de las estelas, en estas tierras del Suroeste: una sociedad de jefaturas consolidadas e ideología -al menos incipientemente- aristocrática (Pavón 1998: 208 y ss.; Harrison 2004), inmersa en paisajes culturales aún por descubrir.

\section{EL PAISAJE CULTURAL DE LAS ESTELAS EN LA SERENA}

Como se desprende de las páginas anteriores, el tipo representado por la estela de Las Bodeguillas se incluye armónicamente entre los ejemplares característicos - desde el punto de vista de la "tipología geográfica"- de la cuenca del Guadiana (Celestino 1990: 5455; 2001: 95-96). Dentro de ella, diversos autores han subrayado en particular la personalidad de su afluente Zújar, más allá de por su fisiografía, por la densidad de hallazgos y frecuencia de agrupaciones (Enríquez y Celestino 1984; Barceló 1989: 191; Galán 1993: 39-41). Abundando en ello, esta zona ha sido considerada como 
una suerte de bisagra, al incluir en su diversidad hasta tres de los seis grupos -calificados como "territorios" por M. Ruiz-Gálvez (1998: 267)- definidos a partir del análisis multivariante de los motivos grabados por Galán (1993: 46-47). Aquí, este autor reconoce concentraciones de estelas prácticamente a la orilla de cada vado; hecho que interpreta como inherente a una zona de frontera en la confluencia de varios territorios políticos, en los que las estelas parecen estar relacionadas con el control de recursos especialmente ganaderos. En esa misma preocupación por la territorialidad, S. Celestino (2001: 54-56 y 293) ha ponderado el interés que ofrece el curso del Zújar más bien como eje caminero, a la hora de posibilitar una unidad donde congregar las diferentes estelas de parte de las comarcas de La Serena y Los Pedroches, también dentro de una dinámica económica pecuaria y en gran medida ovina. Pese a estas sugerentes propuestas, recientemente se ha planteado una cierta autocrítica, no desprovista de algo de razón, sobre los límites de la Arqueología Territorial y del Paisaje aplicada al estudio de las estelas (Enríquez 2007: 107). No obstante, este reconocimiento unánime en el interés de la zona nos obliga a tratar de contextualizar el nuevo hallazgo de Las Bodeguillas al menos en esa escala comarcal y en su paisaje cultural, recabando cuantos datos biogeográficos, arqueológicos y paleoeconómicos puedan ayudarnos a avanzar, hoy por hoy, en su conocimiento.

En este sentido, la comarca de La Serena se podría comparar con un fondo de saco abierto claramente al Guadiana, al noroeste, a través de su comarca de Vegas Altas, si atendemos a sus caracteres orográficos y geológicos. Este vuelco al Guadiana, sin embargo, no impide apreciar otros nexos de unión a través de su red hidrográfica, dotándola de una gran permeabilidad, lo que permitiría la conexión de la misma con comarcas aledañas de las provincias de Córdoba y Ciudad Real a través sobre todo del río Zújar y de su red tributaria. Una conformación que estaría delimitada por los restos de relieves paleozoicos que circundan la comarca, conteniendo en su interior una penillanura de suelos raquíticos y denudados caracterizados por el predominio casi absoluto del complejo esquisto-grauváquico del Precámbrico y los macizos graníticos de su sector suroccidental. Dicho marco geológico general, y con él el edafológico, para la comarca de La Serena es el que ha permitido prever un carácter silvo-pastoril de sus aprovechamientos potenciales, contrastando con la potencialidad agraria que ofrece su aledaña comarca de Vegas Altas donde los recubrimientos aluvio-coluvionares terciarios y cuaternarios son su mejor exponente.
El poblamiento protohistórico de esta definida porción oriental de la provincia de Badajoz adolece aún hoy de un conocimiento profundo. Ello se explica porque no han sido muchas las prospecciones sistemáticas realizadas; de forma que lo que hasta ahora se sabe obedece más bien a búsquedas planteadas para atender a cuestiones puntuales y a hallazgos casuales. En lo que afecta al tiempo de las estelas, al Bronce Final puede adscribirse una serie no muy amplia de yacimientos diversamente valorados, a los que cabría añadir algunos hallazgos aislados, como los propios monolitos grabados, que completan algo más el panorama. No obstante, incluso en aquellos enclaves que han sido recientemente objeto de sondeos arqueológicos, como los altos de Magacela o Entrerríos (Villanueva de La Serena), por unos u otros motivos - principalmente a causa de las intensas ocupaciones posteriores- ha resultado imposible recuperar estructuras de la época bien conservadas, de forma que la documentación se limita a meras trazas de habitación del Bronce Final, reconocibles en fragmentos cerámicos asociados generalmente a los estratos de base. Por otro lado, en función de materiales de superficie, podrían defenderse ocupaciones coetáneas en sitios como el Cerro de El Montón (Helechal) (Martínez 1995 y 1999), el Peñón del Pez (Capilla), Los Villares (Garbayuela), o la Sierra de Las Chimeneas (Talarrubias) (Pavón 1998: 292-293 y 298). Más allá de sus singularidades, todos ellos comparten ciertas características, al ubicarse en altos dotados de buena visibilidad, dispuestos sobre algunas de las sierras que circundan la unidad geográfica en estudio; por lo que, creemos, sugieren un patrón de asentamiento que debió estar relativamente extendido y del que apenas dichas muestras serían sólo una mínima parte. Por el contrario, en el amplio espacio interior de La Serena la nota dominante es la casi total ausencia de información, pues sólo se conoce del hallazgo, aparentemente aislado, de algunas cerámicas similares en el Castillejo de Terciomalillo (Campanario) (Pavón 1998: 297-298); a las que han venido a sumarse las evidencias encontradas en las más recientes prospecciones del entorno de Magacela (Rodríguez, Pavón y Duque 2004: 568). Se adscriben éstas a un posible punto de extracción de malaquita en el llano; patrón de ocupación que, si bien no frecuentemente documentado, tampoco es desconocido en la vega del Guadiana (Rodríguez, Pavón y Duque 2009: 188-190), ni, por lo que se intuye, en La Serena.

Todo ello podría estar marcando una tendencia en lo referente a la elección de emplazamientos, a la que sólo cabe conceder el nivel de hipótesis provisional por los condicionantes ya indicados. Por su parte, 
los conocidos hallazgos aislados en torno a Orellana y Navalvillar de Pela (Almagro Gorbea 1977; Enríquez 1983) podrían igualmente indicar sendos núcleos de población, aún no bien fijados, junto a puntos de vadeo del Guadiana, en la línea de lo ya planteado para otros sitios fuera de nuestra zona de estudio (Pavón 1998: 80-82). Pero, como decíamos, el fenómeno de estelas ha proliferado aquí de forma particularmente notable: a los diversos ejemplares de Cabeza del Buey, Esparragosa de Lares, Navalvillar de Pela, Orellana, Capilla, Zarza Capilla, Benquerencia, Magacela, Cancho Roano, Quintana, El Viso, Belalcázar, etc., catalogados por diversos especialistas, ha venido a sumarse el tercer ejemplar de Esparragosa de Lares que en la primera parte de este estudio hemos dado a conocer (Fig. 6).

Dentro de esta estrategia de contextualización en su paisaje cultural, no debe olvidarse tampoco la inclusión de al menos parte del arte rupestre esquemático del Valle del Zújar, que habría que relacionar en cierto modo con las propias estelas. De hecho, hace ya algunos años Martínez Perelló (1999) llamó la atención acerca de la coincidencia espacial entre los tres principales núcleos rupestres de la Serena oriental -Peñalsordo, Cabeza del Buey y Helechal-y algunas de las conocidas concentraciones de estelas, planteando la posible convivencia de una dualidad (cotidiana y elitista, alternativamente) en el marco de una funcionalidad compartida, la de servir de items señalizadores en el contexto de una economía en gran medida móvil, como la sugerida por Ruiz-Gálvez y Galán (1991). Fuera así o no, esta misma autora llegó a apuntar ciertas similitudes entre algunos antropomorfos y carros de la pintura esquemática -como el guerrero tocado con cuernos del Peñón del Pez, o los carros de la cresta de Los Buitres- y los de las estelas; cuando no la propia existencia de "estelas pintadas”, como la del Pez II (Martínez 1999: 285, 286 y 290). También a su análisis se debe la apreciación de una nítida vinculación de ciertas manifestaciones rupestres a determinados poblados del Bronce Final, como el ya mencionado del Peñón del Pez, o el del Cerro del Montón (Helechal) (Martínez 1995: 226), a los que cabría sumar tal vez, en el límite de la zona de estudio, el de Magacela, al que se podrían acaso asociar algunas de las conocidas pinturas de sus inmediaciones (Gutiérrez 2001: 53 y ss.). Pero, como es sabido, este panorama emergente se ha enriquecido en los últimos años con los sugerentes grabados rupestres del Zújar, entre los que sorprenden las composiciones estelares de guerreros (roca 8) y diademadas (roca 15) del Arroyo Tamujoso (Campanario). A ellos cabe sumar los motivos, que también engalanan las estelas, de espadas, lanzas, escudos, etc. de la roca 21 de ese mismo yacimiento, o de la roca 1 de La Serrezuela (Domínguez y Aldecoa 2007: 319, 349, 370, 374 y 384). Conocidas eran ya por su vinculación cronológica, las problemáticas insculturas de Espejo (Córdoba) (Murillo et alii 2004: 22) en un espacio culturalmente conexo al que estudiamos, o, algo más lejos, las espadas del arte rupestre del Tajo (Gomes 1989: figs. 21 y 24; Brandherm 2007: 25), por mencionar sólo algunos casos. No obstante, justo es reconocer que todos estos hallazgos rupestres de La Serena, pese a dotar de una nueva dimensión contextual a su importante conjunto de monolitos grabados e incentivar su investigación desde nuevas claves espaciales, por el momento no nos permiten esbozar propuestas tan consistentes como las realizadas, por ejemplo, a propósito del arte rupestre de la Edad del Bronce del Noroeste y su significado (Bradley y Fábregas 1996; Criado et alii 2001; Criado y Santos 2006). Pero, sin duda, todas estas expresiones artísticas, pese a la amplitud cronológica desde la que ahora se valoran, no podrán obviarse en todo intento que en el futuro pueda emprenderse para comprender el paisaje cultural de las estelas de La Serena.

Revisada obligadamente de forma sintética esta documentación arqueológica, cabe tal vez añadir que, a nivel secuencial, lo conocido hasta hoy sugiere una dinámica poblacional que tiene cierto interés, en particular en lo que afecta a los momentos avanzados del proceso. Así, como se ha constado recientemente, el final de algunas de las ocupaciones en alto cercanas a la vega del Guadiana antes mencionadas, como las de Magacela y Entrerríos, parece una consecuencia de los proyectos de colonización agraria diseñados desde Medellín. La movilización demográfica, dentro de un marco de continua presencia humana en la zona, que hacia comienzos de la Edad del Hierro esa empresa colonizadora requiere, y que conllevará una ocupación más intensa de la vega hasta definir un verdadero territorio agropolitano en torno al oppidum medellinense, se postula como la causa más viable para explicar - dada la contrastada ausencia de niveles orientalizantes- la extinción de las ocupaciones originarias del Bronce Final tanto en Magacela como en Entrerríos (Rodríguez et alii 2009; Pavón et alii, e.p.). Entretanto, y frente a lo que sucede en dicha vega, no sería descabellado pensar que en ciertas zonas apartadas de La Serena la orientalización resultara mucho más matizada, al igual que se ha propuesto para algunos rincones de la Alta Extremadura (Rodríguez y Pavón 1999: 58; Rodríguez et alii 2001: 130); de manera que el peso de la tradición, en esa realidad de dos velocidades, pudiera haber quedado 


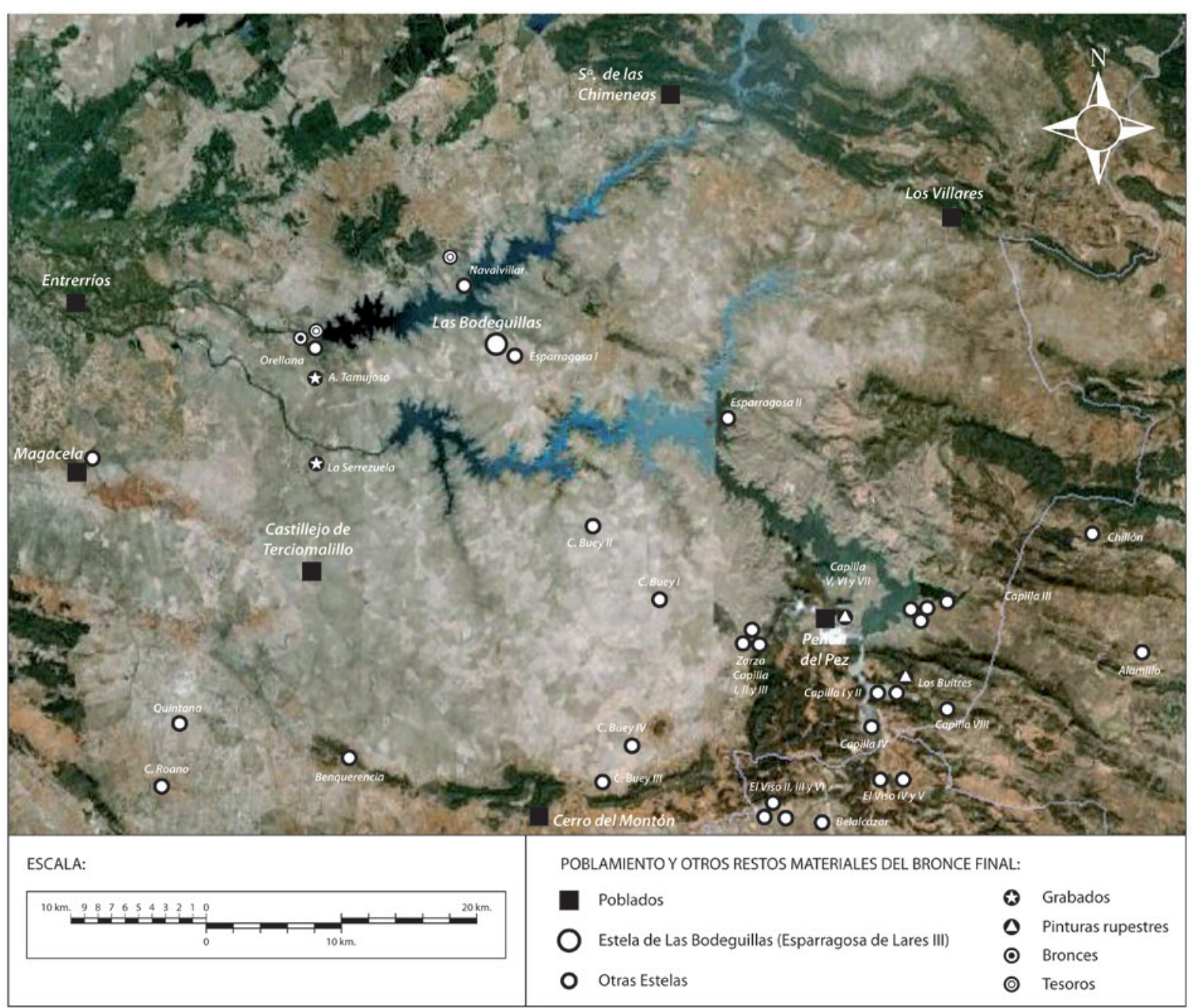

Figura 6. Las estelas extremeñas de La Serena y otras evidencias de poblamiento hacia el final de la Edad del Bronce.

allí reflejado en pervivencias materiales en sintonía con los gustos del Bronce Final. La propia prolongación de las estelas durante al menos parte de la Primera Edad del Hierro, que como otros autores vemos verosímil, sería, a su modo, una suerte de proceso paralelo que creemos intuir, sobre todo, en la concentración percibida hacia el sureste de la zona en estudio, un espacio caracterizado, en principio, por recursos muy distintos de los explotados en la colonizada vega del Guadiana.

Esas pautas paleoeconómicas y la gestión de los recursos potenciales son, por razones obvias, todavía mal conocidas. No obstante, sus trazos gruesos pueden plantearse a la luz de los incipientes estudios realizados. En Magacela, por ejemplo los estudios bioarqueológicos de su fase más antigua (Bronce Final) permiten proponer la existencia de una economía agropecuaria, cuyo impacto sobre el medio circundante no debió de ser muy drástico, según se desprende de la importancia que presentan en sus analíticas las especies arbóreas y arbustivas relacionadas con encinares, alcornocales y bosques riparios (Duque 2004; Grau et alii 2004). Dicha economía se fundamentaba en el cultivo de cereales -cebada vestida y trigo desnudo- y posiblemente leguminosas, acompañada de una ganadería representada por los ovicápridos, los bóvidos y los suidos, además de los équidos (Pérez Jordà, comunicación personal; Castaños Ugarte, comunicación personal). Sólo los siglos orientalizantes habrían de ver, en consonancia con el modelo poblacional ya indicado, una clara tendencia intensificadora en la agricultura de la vega del Guadiana y sus inmediaciones.

Pero, frente a esa orientación más agraria que cabe defender en el valle del Guadiana, resultaría posible plantear, por su parte, un perfil distinto, y complementario, 
en los rebordes montuosos de La Serena. Es evidente que no se cuenta con datos paleoeconómicos concluyentes, pero, a falta de ellos, un análisis de las potencialidades suscita la posible explotación de diversos minerales metálicos que abundan por esos pagos, ampliando el abanico de una economía basada casi exclusivamente en los pastos que buena parte de los investigadores, como hemos visto, señalan. En particular, no debe pasar desapercibida -dejando a un lado otros indicios menores- la abundancia de galenas y mineralizaciones de cobre en el campo filoniano de Peñalsordo-CapillaCabeza del Buey (IGME 2006: 22-23), zona en la que, como hemos visto, se da una reseñable concentración de estelas. A nivel arqueológico, está constatado el uso -y entendemos que la necesidad- del cobre, plomo y estaño por los grupos implicados en la colonización agrícola que se despliega en torno a Medellín desde comienzos del Hierro (Rovira,2008 y 2009); una demanda que haría interesante la explotación de estos recursos en zonas de su periferia, incluso con anterioridad. Hace años, ya llamamos la atención sobre la viabilidad de contemplar la actividad extractiva y transformadora de la casiterita cacereña, en particular de Logrosán y tal vez de las inmediaciones de la Sierra de Montánchez -zonas también dotadas de muy conocidas estelas, dicho sea de paso- en relación con una demanda que tendría como destino inmediato, a través de distintos cauces, el Guadiana Medio (Rodríguez et alii 2001: 140); un discurso que, planteamos ahora, podría hacerse tal vez extensivo, para las galenas y el mineral de cobre, a las poblaciones de las estribaciones meridionales de La Serena. Cabe añadir, además, que en los últimos años se han detectado indicios de labores -calificadas de muy antiguas por sus prospectores- de extracción de oro entre Talarrubias y Casas de Don Pedro (IGME 2006: 31-32), en el piedemonte de la Sierra de Las Chimeneas, que, al igual que se ha planteado para el Tajo o la penillanura cacereña, sugerirían atender también al interés por localizaciones puntuales de este metal precioso en el propio Guadiana. Pero este hipotético interés por la minería no es, en cualquier caso, algo especial ni exclusivo de esta zona; pues en el vecino norte cordobés, también pródigo en estelas de guerrero, J. F. Murillo (1994b: 452-455) ya señaló un buen número de asentamientos, adscritos a un momento avanzado del Bronce Final y al Orientalizante, que relacionar con el aprovechamiento del cobre, plomo argentífero y estaño de sus territorios de producción restringida, desde donde se trasladaría a escenarios más meridionales, ya a orillas del Guadalquivir.

No queremos decir con ello que la economía de este espacio fuera básicamente minero-metalúrgica, sino que, además de la agricultura y los afamados pastos, los recursos metálicos, que existían -e incluso eran abundantes-, tenían su demanda y, convenientemente transformados, proporcionaban un prestigio sobre el que parece haber pocas dudas, bien pudieran haber movilizado también a esos grupos humanos cuyo poder, en estas zonas marcadamente rurales, con tanta reiteración tiende a expresarse a través de las estelas. Una naturaleza dispersa y variada de los recursos que se prestaría especialmente al concurso de "confederaciones de jefaturas individualistas” (Pavón y Rodríguez 2007: 18), o, dicho de otro modo, a la aplicación de "modelos heterárquicos" en la comprensión general del proceso (Rodríguez 2009: 62), al requerirse múltiples interacciones para conseguir explotar y gestionar tal mosaico de potencialidades (Fig. 7). En suma, todos estos argumentos, poblacionales, culturales y económicos, nos parecen suficientes para plantear la contemplación de La Serena bajo el prisma del mismo "modelo simbiótico", apoyado en la variabilidad y complementariedad de recursos agrícolas, ganaderos y metalúrgicos, que venimos proponiendo desde hace tiempo para el poblamiento de otros espacios del Suroeste hacia comienzos de la Protohistoria (Pavón 1999)3 . Un telón de fondo indudablemente generador de circuitos y caminos, pero también de realidades humanas estables, sobre el que repensar el sentido de las estelas y su mensaje.

\section{VALORACIÓN FINAL}

Lejos de poner en cuestión las posibilidades que ofrece la Arqueología del Territorio para la comprensión del fenómeno de las estelas decoradas o extremeñas, hemos apostado aquí por la oportunidad de estudiar dichas manifestaciones en su paisaje cultural. Convencidos de que difícilmente pueda dársele una única explicación global más allá de en sus aspectos generales, el hallazgo de un nuevo ejemplar en la localidad badajocense de Esparragosa de Lares nos ha conducido, tras su presentación en la primera parte de este trabajo, a la búsqueda de su contexto en una escala comarcal. Como se desprende de lo expresado en páginas

3. En la actualidad, desde nuestro grupo de investigación venimos profundizando en las singularidades de dicho modelo, más allá del Guadiana, en otras comarcas extremeñas a lo largo del Bronce Final-Orientalizante. Así, en el marco del Proyecto de Investigación que lleva por título "El tiempo del tesoro de Aliseda" (HAR 201014917) (I+D MICINN), tratamos de caracterizarlas en el entorno del poblado al que cabe vincular el célebre tesoro, en el espacio Sierra de San Pedro/Montánchez-Penillanura Cacereña. 


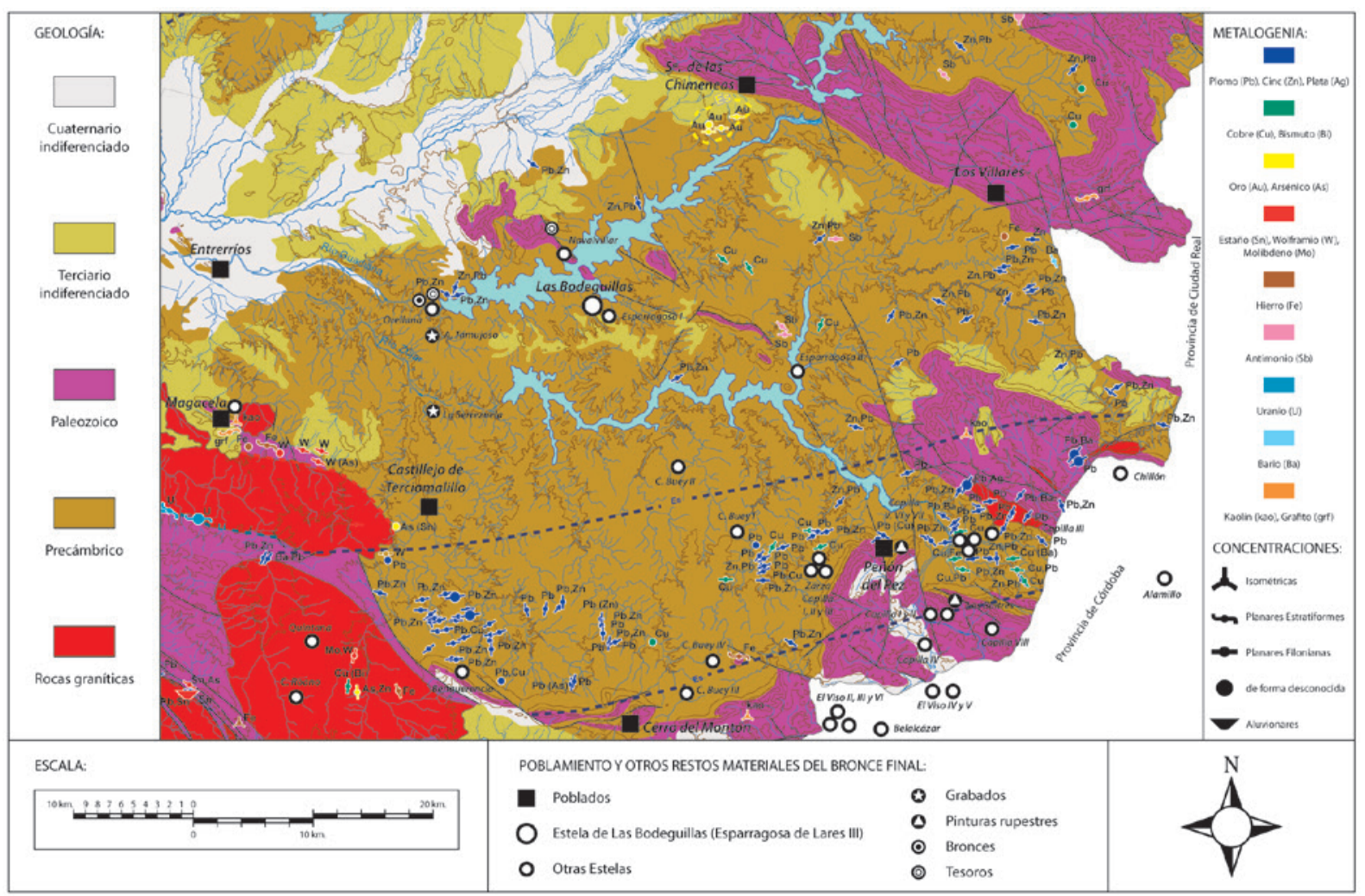

Figura 7. Estelas, poblamiento del Bronce Final y recursos potenciales en el sureste de Badajoz.

anteriores, la hallada en Las Bodeguillas ofrece rasgos compositivos y estilísticos relativamente comunes entre el grupo de estelas "del valle del Guadiana" y afines, con todas las reservas a que obliga el esquematismo de sus motivos, a lo que se tiende a considerar representativo de los ejemplares avanzados de la serie, posiblemente en la fase transicional Bronce Final-Hierro I. Más específicamente, viene a sumarse al amplio conjunto de manifestaciones de La Serena -en la mitad oriental de la provincia de Badajoz-, puestas unas veces en relación con una suerte de frontera entre varios territorios y otras con una ruta de comunicación entre los cursos medios del Guadiana y el Guadalquivir vía Zújar.

Con todos los condicionantes que el estado de la cuestión impone, la suma de indicios arqueológicos sugiere la imbricación de las estelas de la zona en un modelo de poblamiento vinculado a la explotación integral de los recursos, con una cierta predilección por la disposición de los hábitats en cotas altas y enclaves con un cierto dominio visual, en modo alguno extraño a los patrones al uso en la región extremeña y, en general, en el occidente hispano. Hacia el Bronce Final-Hierro I, parece clara la reestructuración, al menos en parte de la Baja Extremadura, de estos esquemas. Así, la constatación del arranque de un programa de intensificación agraria, particularmente evidente en la colonización del entorno del oppidum de Medellín, se aventura parejo al abandono de otros cercanos poblados en alto, como Magacela o Entrerríos, cuya población se relocalizaría en las tierras bajas. Un proceso más matizado de “orientalización" es el que, por el contrario, se intuye en los rebordes serranos, tan abundantes en monolitos grabados. Allí, a inspiración de lo constatado en las sierras centrales de Extremadura, creemos posible la pervivencia de un poblamiento anclado en los esquemas socioeconómicos y culturales tradicionales, y más atento tal vez a la explotación de los recursos mineros y su control. Demandado aún en gran medida por las poblaciones asentadas en el valle, dentro de un marco de complementariedad, la gestión del metal podría haber sido, junto a los recursos agro-silvo-pastoriles, el sostén económico esencial de las élites rurales representadas en las estelas de esta zona, a las que ahora se viene a sumar la nueva estela de guerrero de Las Bodeguillas. 


\section{BIBLIOGRAFÍA}

ALMAGRO BASCH, M. (1966): Las estelas decoradas del suroeste peninsular. Bibliotheca Praehistorica Hispana VIII. Madrid.

ALMAGRO GORBEA, M. (1977): El Bronce Final y el Periodo Orientalizante en Extremadura. Bibliotheca Praehistorica Hispana XIV. Madrid.

BARCELÓ, J. (1989): "Las estelas decoradas del sudoeste de la Península Ibérica", en M. E. Aubet (coord.): Tartessos. Arqueología protohistórica del Bajo Guadalquivir: 189-208. Ausa, Sabadell.

BENDALA, M. (2000): Tartesios, iberos y celtas. Pueblos, culturas y colonizadores de la Hispania Antigua. Temas de hoy, Madrid.

BERNIER, J. (1969): "Una nueva estela grabada junto a las murallas ibéricas de Ategua en la provincia de Córdoba", Zephyrus XIX-XX: 180-182.

BRADLEY, R. y FÁBREGAS, R. (1996): “Petroglifos gallegos y arte esquemático: una propuesta de trabajo", en A. Querol y T. Chapa (eds.), Homenaje al Profesor M. Fernández Miranda. Complutum Extra 6-II: 103-110.

BRANDHERM, D. (2007): Las Espadas del Bronce Final en la Península Ibérica y Baleares, Prähistorische Bronzefunde, Abteilung IV, 16. Band, Franz Steiner Verlag Stuttgart.

DOMÍNGUEZ, C.; GONZÁLEZ, J. M. y DE HOZ, J. (2005): Estelas decoradas del Museo Arqueológico Provincial de Badajoz. Siglos VIII-V a.C. Consejería de Cultura, Junta de Extremadura, Badajoz.

DUQUE, D. (2004): La gestión del paisaje vegetal en la Prehistoria Reciente y Protohistoria en la Cuenca Media del Guadiana a partir de la Antracología. Tesis Doctoral. Universidad de Extremadura. Cáceres. http://dialnet.unirioja.es/servlet/tesis? codigo $=199$

CELESTINO, S. (1990): "Las estelas decoradas del SW peninsular", La cultura tartésica y Extremadura. Cuadernos Emeritenses 2: 45-62.

- (2001): Estelas de guerrero y estelas diademadas. La precolonización y formación del mundo tartésico. Bellaterra Arqueología, Barcelona.

- (2008): "La precolonización a través de los símbolos", en S. Celestino, N. Rafel y X. L. Armada (eds.), Contacto cultural entre el Mediterráneo y el Atlántico (siglos XII-VIII ane). La precolonización a debate: 107-119. CISC, Madrid.

CRIADO, F. y SANTOS, M. (2006): "Paisajes domésticos, espacios cerrados: los espacios de la representación y la domesticación del paisaje en la Edad del Bronce", en J. Martínez y M. Hernández (eds.), Arte rupestre esquemático en la Península Ibérica. Comarca de los Vélez: 173-192.

CRIADO, F., FÁBREGAS, R. y SANTOS, M. (2001): "Paisaje y representación en la Edad del Bronce: la descodificación del arte rupestre gallego", en M. Ruiz-Gálvez (coord.), La Edad del Bronce, ¿Primera Edad de Oro de España?: 291-320. Crítica, Barcelona

DOMÍNGUEZ, A. y ALDECOA, M. A. (2007): Arte Rupestre en la ZEPA de La Serena: Puebla de Alcocer, Esparragosa de Lares y Campanario, en H. Collado y J. J. García (coords.), Corpus de Arte Rupestre en Extremadura, Vol. II. Junta de Extremadura, Mérida.

ENRÍQUEZ, J. J. (1983): "Una nueva estela de guerrero y tres asadores de bronce procedentes de los alrededores de Orellana la Vieja (Badajoz)", $M u$ seos 2: 10 y ss.

- (2006): “Arqueología rural y estelas del SO (desde la tierra, para la tierra y por la tierra)", Cuadernos de Arqueología de la Universidad de Navarra 14: 151-175.

- (2007): "El papel de la muerte y la ideología funeraria en la protohistoria extremeña", en A. Rodríguez e I. Pavón (eds.), Arqueología de la tierra. Paisajes rurales de la protohistoria peninsular: 103-128. Universidad de Extremadura, Cáceres.

ENRÍQUEZ, J. J. y CELESTINO, S. (1984): "Nuevas estelas decoradas en la cuenca del Guadiana", Trabajos de Prehistoria 41: 237-250.

ESTEPA, J. J. (2000): Las grandes cañadas extremeñas. Relatos de la Mesta. Universitas Editorial, Badajoz.

FERNÁNDEZ, J. R. (1950): "Lápidas sepulcrales de la Edad del Bronce en Extremadura", Archivo Español de Arqueología 78: 290-301.

FERRER ALBELDA, E. (1999): "La estela decorada de Montemayor (Córdoba)", Antiquitas 10: 65-71.

GALÁN, E. (1993): Estelas, paisaje y territorio en el Bronce Final del Suroeste de la Península Ibérica. Complutum Extra 3.

GARCÍA, L. (1999): Los orígenes de la estratificación social. Patrones de desigualdad en la Edad del Bronce del Suroeste de la Península Ibérica (Sierra Morena Occidental c. 1700-1100 a.n.e./2100-1300 A.N.E.). BAR International Series 823. Oxford.

GARCÍA, L.; WHEATLEY, D. W.; FÁBREGA, P.; HERNÁNDEZ, M. J. y POLVORINOS, A. (2006): "Las estelas de guerrero de Almacén de la Plata (Sevilla). Morfología, tecnología y contexto", Trabajos de Prehistoria 63-2: 135-152. 
GOMES, M. VARELA (1989): “Arte rupestre do Vale do Tejo, um santuário pré-histórico", Encuentros sobre el Tajo: el agua y los asentamientos humanos (Alcántara-Lisboa, 15 al 19 de febrero de 1988). Cuadernos de San Benito 2: 49-75.

GOMES, M. VARELA y MONTEIRO, J. PINHO (1977): "Las estelas decoradas do Pomar (Beja-Portugal) estudo comparado", Trabajos de Prehistoria 34: 165-214.

GRAU, E.; DUQUE, D. M. y CUENCA, C. (2004): "Paleoambiente y paisaje en La Serena", en A. Rodríguez (ed.), El edificio protohistórico de "La Mata" (Campanario, Badajoz) y su estudio territorial: 29-72. Servicio de Publicaciones de la Universidad de Extremadura, Cáceres

GUTIÉRREZ, A. (2001): Magacela. El patrimonio de un municipio de la Orden de Alcántara. Diputación de Badajoz, Badajoz.

HARRISON, R. J. (2004): Symbols and Warriors. Images of the European Bronze Age. Western Academic \& Specialist Press Limited, Bristol.

IGME (2006): Mapa metalogenético de la provincia de Badajoz Escala 1:200.000. Madrid.

MAC WHITE, E. (1947): "Sobre unas losas grabadas en el suroeste de la Península Hispánica y el problema de los escudos tipo Herzsprung", Actas y Memorias de la Sociedad Española de Antropología, Etnología y Prehistoria 22: 158-166 y lám. XVIII.

MARTÍNEZ, M. I. (1995): "Los abrigos pintados de Helechal: un nuevo conjunto de arte rupestre esquemático en Badajoz", Espacio, Tiempo y Forma. Serie I, Prehistoria y Arqueología 8: 191-233.

- (1999): "El Valle del Zújar: un importante enclave para el arte rupestre esquemático en Badajoz", Espacio, Tiempo y Forma. Serie I, Prehistoria y Arqueología 12: 269-293.

MEDEROS, A. y HARRISON, R. J. (1996): “Patronazgo y clientelas. Honor, guerra y festines en las relaciones sociales de dependencia del Bronce Final Atlántico en la Península Ibérica", Pyrenae 27: 31-52.

MURILLO, J. F. (1994 a): "La estela de la Ribera Alta (Córdoba): consideraciones en torno a las estelas decoradas con escudo, espada y lanza", Anales de Arqueología Cordobesa 5: 11-32.

- (1994 b): La cultura tartésica en el Guadalquivir Medio. Ariadna 13-14. Museo Municipal de Palma del Río.

MURILLO, J. F.; MORENA, J. A. y RUIZ, D. (2005): "Nuevas estelas de guerrero procedentes de las provincias de Córdoba y de Ciudad Real", Romula 4: 7-46.
PAVÓN, I. (1998): El tránsito del II al I milenio a.C. en las cuencas medias de los ríos Tajo y Guadiana: La Edad del Bronce. Servicio de Publicaciones de la Universidad de Extremadura, Cáceres.

- (1999): "Los albores de la protohistoria en la mesopotamía extremeña: notas para la discusión de un modelo", Estudos Pré-Históricos VII: 179-212.

- (e.p.): "Nunca fuimos héroes. A propósito de una percepción europea de las estelas extremeñas", El arte en tiempo de cambio y crisis. Actas de las XI Jornadas de Historia en Llerena. Llerena, 22 y 23 de octubre de 2010. Sociedad Extremeña de Historia.

PAVÓN, I. y RODRÍGUEZ, A. (2007): “Campo y ciudad en la protohistoria extremeña: conceptos y criterios investigadores", en A. Rodríguez e I. Pavón (eds.), Arqueología de la tierra. Paisajes rurales de la protohistoria peninsular: 11-44. Universidad de Extremadura, Cáceres

PAVÓN, I.; RODRÍGUEZ, A. y DUQUE, D. M. (e.p.): "Contexto territorial e histórico", en A. Rodríguez, I. Pavón y D. M. Duque (eds.), El poblado prerromano de Entrerrios (Villanueva de La Serena, Badajoz). Campaña de 2008. Memorias de Arqueología Extremeña 13. Mérida.

PINGEL, V. (1974): "Bemerkungen zu den ritzverzierten Stelen und zur beginnenden Eisenzeit un Südwesten der Iberische Halbinsel", Hamburger Beiträge zur Archäologie 4: 1-19.

RODRÍGUEZ, A. (2009): Campesinos y "señores del campo". Tierra y poder en la protohistoria extremeña. Bellaterra, Barcelona.

RODRÍGUEZ, A. y PAVÓN, I. (1999): El poblado protohistórico de Aliseda (Cáceres). Campaña de 1995. Ayuntamiento de Aliseda, Cáceres.

RODRÍGUEZ, A.; PAVÓN, I. y DUQUE, D. M. (2004): "La Mata y su territorio", en A. Rodríguez (ed.), El edificio protohistórico de "La Mata" (Campanario, Badajoz) y su estudio territorial: 497-569. Servicio de Publicaciones de la Universidad de Extremadura, Cáceres.

RODRÍGUEZ, A., PAVÓN, I. y DUQUE, D. M. (2009): “Contexto territorial e histórico", en A. Rodríguez, D. M. Duque e I. Pavón (eds.), El caserío de Cerro Manzanillo (Villar de Rena, Badajoz) y la colonización agraria orientalizante en el Guadiana Medio. Memorias de Arqueología Extremeña 12: 183-322. Mérida.

RODRÍGUEZ, A.; PAVÓN, I.; MERIDETH, C. y JUAN, J. (2001): El Cerro de San Cristóbal, Logrosán, Extremadura, Spain. The archaeometallurgical excavation of a Late Bronze Age tin-mining and 
metalworking site. First excavation season 1998. BAR International Series 922. Oxford.

RODRÍGUEZ, M. (2004): La trashumancia. Culturas, cañadas y viajes, (4 edición revisada y ampliada). Edilesa, León.

ROSO, M. (1898): "Losa sepulcral de Solana de Cabañas en el partido de Logrosán (Cáceres)", Boletín de la Real Academia de la Historia 32: 179-182.

ROVIRA, S. (2008): “Aspectos metalúrgicos del yacimiento orientalizante de Medellín", en M. Almagro Gorbea (dir.): La necrópolis de Medellín. III-IV-V. Bibliotheca Archaeologica Hispana 263: 847-852.

ROVIRA, S. (2009): "Restos metálicos y metalúrgicos", en A. Rodríguez, D. M. Duque e I. Pavón (eds.), El caserío de Cerro Manzanillo (Villar de Rena, Badajoz) y la colonización agraria orientalizante en el Guadiana Medio. Memorias de Arqueología Extremeña 12: 171-173. Mérida.
RUIZ, A. (1996): "Desarrollo y consolidación de la ideología aristocrática entre los iberos de sur”, Coloquio Internacional Iconografía Ibérica, Iconografía Itálica: propuestas de interpretación y lectura. Serie Varia 3: 61-71. Universidad Autónoma de Madrid.

RUIZ-GÁLVEZ, M. L. (1998): La Europa atlántica en la Edad del Bronce. Un viaje a las raíces de la Europa occidental. Crítica, Barcelona.

RUIZ-GÁLVEZ, M. L. y GALÁN, E. (1991): “Las estelas del Suroeste como hitos de vías ganaderas y rutas comerciales", Trabajos de Prehistoria 48: 257-273.

TEJERA, A.; FERNÁNDEZ, J. y RODRÍGUEZ, M. (2006): "Las estelas tartésicas: ¿losas sepulcrales, marcadores étnicos o representación de divinidades guerreras?", Spal 15: 149-165. http://dx.doi. org/10.12795/spal.2006.i15.07

VALIENTE, J. y PRADO, S. (1978): “Estelas decoradas de Aldea del Rey (Ciudad Real)", Archivo Español de Arqueología 50-51: 375-379.

Fecha de ENTRADA: 20-04-2011

FECHA DE ACEPTACIÓN: 13-05-2011 